\section{Pharmaceutical Patient Assistance Programs: Don't Look a Gift Horse in the Mouth or There's No Such Thing as a Free Lunch}

The affordability of prescription drugs is a major problem for many Americans. For at least the last decade, almost 17\% of the under65-years population-approximately 41 million individualshas been without health insurance. ${ }^{1}$ In addition, a substantial number of consumers who are insured at some point during any given year are uninsured at other times during the year. Families USA reported that about 81.8 million Americans under the age of 65 lacked health insurance at some point during the 2003-2004 period. ${ }^{2}$ They further reported that two thirds of this number were uninsured for 6 or more months and 51\% were uninsured for 9 or more months. ${ }^{2}$ Gupta et al. have reported that about $12.5 \%$ of working age (18-64 years) adults in the United States experienced periods where they lacked insurance for prescription drugs during 2000. ${ }^{3}$ This was in addition to the $21.5 \%$ that lacked prescription drug insurance for all of $2000 .^{3}$

Even consumers who are covered by prescription drug insurance may have trouble affording prescription drugs. The Center for Studying Health System Change reported that, during 2003, 15.2\% of privately insured working age adults (those aged 18-64 years) with chronic health conditions failed to get needed prescription medicines at least once in the previous 12 months because they could not afford them. ${ }^{4}$ This amounted to 5.5 million adults who had jobs and insurance and yet could not afford needed medications at some time during the year. Piette et al. have reported that $17 \%$ of a national sample of individuals aged 50 years and older who took medication for diabetes, depression, heart problems, hypertension, or high cholesterol reported taking "less of their medication in the prior 12 months because of the cost." ${ }^{\text {s }}$

Affordability of prescription drugs is a problem for many insured patients in part because of increased use of tiered formularies and increased patient cost sharing ${ }^{4}$ as well as the higher prices of new prescription products. The Kaiser Family Foundation reports that the average community pharmacy prescription price increased from $\$ 28.67$ in 1994 to $\$ 68.26$ in 2006 . These trends suggest that the problem of affordability of prescription drugs is likely to grow in the foreseeable future.

Affordability is an especially significant problem for those on specialty pharmaceuticals. These products are substantially more expensive than traditional, chemical-based products. The Express Scripts Drug Trend Report indicates that the average cost of a prescription for a specialty product in 2006 was $\$ 1,454 .^{7}$ Patients typically filled between 4 and 10 prescriptions per year for each specialty product prescribed for them. The Wall Street Journal reported that the price for cancer treatment with specialty products can range from $\$ 36,000$ to $\$ 56,000$ per patient. ${ }^{8}$ Some insurers have created specialty copayment tiers in pharmacy benefits for these products that require patient coinsurance of $20 \%$ to $50 \% .{ }^{9}$ Even though coinsurance payments in these programs are often limited by out-of-pocket payment limits of $\$ 100$ to $\$ 250$ per prescription fill, these coinsurance amounts may exceed the ability to pay for many health plan members. Further, the high cost of most specialty products, many for chronic conditions, contributes to total medical costs that can push patients over insurance policy life-time maximum amounts, leaving them without insurance coverage. A recent Wall Street Journal article noted that the cost of treatment with Myozyme, a specialty drug used to treat a rare enzyme disorder, may be as much as $\$ 300,000$ per year. ${ }^{10}$

Pharmaceutical company patient assistance programs (PAPs) offer one potential solution to the problem of affordability of prescription drugs. These programs provide pharmaceuticals to medically indigent patients for free or for substantially reduced prices. The Pharmaceutical Research and Manufacturers Association (PhRMA) indicates that these programs provided $\$ 5$ billion worth of free drugs to needy consumers in $2005 .{ }^{11} \mathrm{~A}$ number of studies have documented the savings generated by these programs for consumers, health centers, and hospitals. For example, Sarrafizadeh et al. reported that a private ambulatory care clinic in upstate New York saved $\$ 48,143$ by using patient assistance programs for 44 patients during a 1-year study period. ${ }^{12}$ Johnson indicated that the H. Lee Moffitt Cancer Center saved $\$ 1.5$ million in 2006 as a result of using PAPs for indigent patients. ${ }^{13}$ Hotchkiss reported savings of $\$ 7,000$ per month in a state psychiatric facility that served about 48 patients each month. ${ }^{14}$ Chisholm et al. indicated that use of PAPs resulted in cost avoidance of between $\$ 69,000$ and $\$ 125,000$ in a transplant clinic in a university teaching hospital for the 1998 calendar year. ${ }^{15}$ Coleman et al. reported net savings of $\$ 57,000$ over 6 months for indigent inpatients in a Connecticut hospital. ${ }^{16}$

As Clay et al. documented in an article in a previous issue of JMCP, PAPs are not without costs. ${ }^{17}$ While the drug product may be provided free of charge, the health care provider or organization realizes substantial costs in applying for and distributing the products. An application must be submitted for each product requested. Different manufacturers have different application processes, many of which are complicated and lengthy. Some applications require documentation of patient need or require that documentation includes the patient's tax returns. While some manufacturers allow for refills, many require a new application for each refill. Application processes may change without notice at any time. Pharmacists, social workers, and/or trained clerical personnel are typically involved in completing application forms and applications always require some degree of physician involvement. In a national survey of safety net clinics, Duke et al. reported that the most common reason for not using PAPs was that they were "too time consuming and complex,"18 followed closely by "unrealistic income documentation requirements for indigent patients."18

Large providers, such as pharmacies in university teaching hospitals, may have fewer problems administering PAPs because their large scale may allow the use of bulk replacement programs. These allow pharmacies to dispense PAP products to indigent patients without completing the manufacturer application 
process. Most hospitals have financial counselors or financial assistance specialists who determine patients' insurance status and ability to pay their hospital charges. These same financial assistance specialists can be used to determine whether patients qualify for PAPs. Once individuals are deemed to be qualified by the financial counselor, the pharmacy dispenses their PAP medications and notes that the medications were dispensed for a PAP patient. At the end of each month (or quarter, depending in the manufacturer's policy), the pharmacy determines the quantity of each manufacturer's drugs dispensed to PAP patients and sends a report with this information to the manufacturer. The manufacturer then ships the pharmacy a sufficient quantity of each product to replace what was dispensed to PAP patients.

The costs that providers, institutions, and patients incur in using PAPs have not been well documented. Most of the available research has been limited to estimation of the short-term, direct costs of operating PAPs from the health care institution's perspective. ${ }^{14-16,18,19}$ Most researchers have focused on the costs of pharmacists, technicians, and other employees—such as social workers or patient registration technicians-employed to manage the process of applying for and dispensing PAP drugs. For the most part, these studies have not included valuation of physician's time, overhead costs to the institution, or patients' time. However, the magnitude of savings that have been attributed to PAPs suggest that they would be cost-effective even after consideration of these additional costs. In one of the most comprehensive cost studies, Richardson and Basskin surveyed a national sample of safety net clinics and hospitals in 2000. ${ }^{20}$ They calculated the net benefit of PAPs by subtracting the cost of providing the program from the total value of medications received through the programs; the 340B acquisition prices were used to value the medications. Costs included labor, equipment, and miscellaneous (i.e., postage and mailing). The median annual net benefit for their sample ranged from $\$ 48,000$ for clinics with outpatient medication budgets under $\$ 500,000$ to $\$ 877,000$ for hospitals with outpatient medication budgets over $\$ 500,000$.

PAPs may also be associated with costs that are longer-term and more difficult to quantify. PAPs operated by the research-intensive pharmaceutical companies, which operate the great majority of PAPs, are almost always restricted to expensive, patented, brandname products. Consequently, physicians who treat medically indigent patients frequently face the choice of providing a "free" PAP drug or an equally effective generic alternative. While the PAP drug is cheaper in the short run, it may be more expensive to both the health care system and the patient in the long run. In the short run, the "free" drug solves the physician's problem of providing therapy to a patient unable to pay for needed prescriptions. In the long run, however, PAPs may increase costs.

First, the use of PAP drugs may disrupt the formulary process. ${ }^{21}$ Physicians may become accustomed to using expensive, non-formulary PAP products rather than the generally less expensive formulary products. To the extent that this practice spills over to prescribing for non-indigent patients, health system costs increase. If, or when, PAP coverage ends, the patient faces paying for a much more expensive product or being switched to another product. Switching products is also not without costs; patients may be required to make additional physician visits and undergo additional laboratory tests to be stabilized on the new drug. Similarly, if an uninsured patient gains insurance coverage, the insurance company must either pay for a more expensive product or pay to have the patient switched to a new product.

Second, PAPs may also deflect attention from finding a more comprehensive solution to the problem of affordable drugs. The existence of PAPs supports the illusion that affordability of prescription drugs is not a problem because there is a mechanism through which all patients, regardless of income, can get the drugs they need. In fact, there are large numbers of consumers who are unable to afford needed prescription drugs and who are ineligible for or unaware of PAPs. The Partnership for Prescription Assistance program, which includes but is not restricted to pharmaceutical company PAPs, provided prescription drugs for more than 3.6 million consumers in its first 2 years of existence, from April 2005 to April 2007. ${ }^{11}$ While this is a substantial number of consumers, it is a fraction of the 81.8 million without insurance at sometime during that period. ${ }^{2}$ Further, it is a smaller number than the 5.5 million working and privately insured consumers who did not get needed medicines due to cost concerns during 2003. ${ }^{4}$

Finally, PAP drugs, like all products and services, cannot be provided free of cost. Their cost is ultimately borne by cash-paying consumers in the form of higher drug prices and by insured consumers in the form of higher insurance premiums, deductibles, and copayments. PAP drugs are best used as part of a comprehensive program of therapeutic selection in which PAPs are one component of a multifaceted strategy to improve access to medications, such as the pharmacist-directed intervention described previously in JMCP by Stebbins et al. for one large medical group California.22

How one views PAPs depends on one's perspective. In the short run, they provide billions of dollars of prescription drugs to consumers who might otherwise be denied needed drug therapy. In the long run, PAPs may actually exacerbate the problem of access to prescription drugs by deflecting concern about the issue of affordability and by contributing to the use of higher-cost drugs. Despite their long-term costs, it seems likely that PAPs will continue to be necessary and heavily-used until a more comprehensive solution to the problem of prescription drug affordability is developed.

Norman V. Carroll, PhD, RPh
Professor, Division of Pharmacy Administration
School of Pharmacy
Virginia Commonwealth University
410 N. 12th St.
PO Box 980533
Richmond, VA 23298-0533
nvcarroll@vcu.edu




\section{DISCLOSURES}

The author discloses no potential bias or conflict of interest relating to the subject of this article.

\section{REFERENCES}

1. National Center for Health Statistics. Health, United States, 2006: with chartbook on trends in the health of Americans. Hyattsville, MD: National Center for Health Statistics; 2006.

2. Stoll K, Jones K. One in three: non-elderly Americans without health insurance, 2002-2003. Washington, DC: Families USA; 2004.

3. Gupta K, Cline RR, Schondelmeyer SN. Drug insurance instability and its correlates: results from the 2000 Medical Expenditure Panel Survey. Res Soc Admin Pharm. 2006;2(2):232-53.

4. Reed M. An update on Americans' access to prescription drugs: Issue Brief 95. Washington, DC: Center for Studying Health System Change; 2005.

5. Piette JD, Heisler M, Wagner TH. Cost-related medication under use: do patients with chronic illnesses tell their doctors? Arch Intern Med 2004;164: 1749-55.

6. Prescription drug trends: May 2007. Available at: http://www.kff.org/ rxdrugs/3057.cfm. Accessed June 22, 2007.

7. Meyer J, Parker A, Tharaldson A, Peterson C. Express drug trends report: 2006. Maryland Heights, MO: Express Scripts; 2007.

8. Anand G. Prescribing caution from Wall Street: a warning about cancerdrug prices. Wall Street Journal. March 15, 2007:A1.

9. EMD Serono. Serono injectables digest. Rockland, MA: EMD Serono; 2005.

10. Armstrong D, Anand G. Genzyme's hit turns headache. Wall Street Journal. August 9, 2007. Available at: http://online.wsj.

com/article_print/SB118662029282192459.html. Accessed August 10, 2007.

11. Pharmaceutical Research and Manufacturers Association (PhRMA). 2006 Industry Profile. Washington, DC: PhRMA; 2006.
12. Sarrafizadeh M, Waite NM, Hobson EH, Migden H. Pharmacist-facilitated enrollment in medication assistance programs in a private ambulatory care clinic. Am J Health Syst Pharm. 2004;61(17):1816-20.

13. Johnson PE. Patient assistance programs and patient advocacy foundations: alternatives for obtaining prescription medications when insurance fails. Am J Health Syst Pharm. 2006; 63(21 suppl 7):S13-S17.

14. Hotchkiss BD, Pearson C, Lisitano R. Pharmacy coordination of an indigent care program in a psychiatric facility. Am J Health Syst Pharm. 1998;55:1293-96.

15. Chisholm MA, Vollenweider LJ, Mulloy LL, Wynn JJ, Wade WE, DiPiro JT. Cost-benefit analysis of a clinical pharmacist-managed medication assistance program in a renal transplant clinic. Clin Transplant. 2000;14(4 pt 1):304-07.

16. Coleman CI, Reddy P, Quericia RA, Gousse G. Cost-benefit analysis of a pharmacy-managed medication assistance program for hospitalized patients. Am J Health Syst Pharm. 2003;60:378-82.

17. Clay P, Vaught E, Glaros A, Dietz C, Mangum S. Costs to physician offices of providing medications to medically indigent patients via pharmaceutical manufacturer prescription assistance programs. J Manag Care Pharm. 2007;13(6): 506-14. Available at: http://www.amcp.org/data/jmcp/pages\%20506-514.pdf.

18. Duke KS, Raube K, Lipton HL. Patient-assistance programs: assessment of and use by safety-net clinics. Am J Health Syst Pharm. 2005;62(7):726-31.

19. Decane BE, Chapman J. Program for procurement of drugs for indigent patients. Am J Hosp Pharm. 1994;51:669-71.

20. Richardson K, Basskin LE. Use of drug manufacturers' patient assistance programs by safety net providers. Am J Health Syst Pharm. 2002;59(11):1105-09.

21. Van Diepen LR. Pharmaceutical manufacturer assistance programs for indigent patients: solution or symptom? Am J Health Syst Pharm. 2001;58(2): 162-63.

22. Stebbins MR, Kaufman DJ, Lipton HL. The PRICE Clinic for low-income elderly: a managed care model for implementing pharmacist-directed services. J Manag Care Pharm. 2005;11(4):333-41. Available at: http://www.amcp.org/ data/jmcp/contemporary_333_341.pdf. 